\title{
CULTURA MATERIAL ESCOLAR: ANÁLISE DO LIVRO ESTUDO DIRIGIDO DE EDUCAÇÃO MORAL E CÍVICA DE 1975
}

\author{
Franciele Daiane Rodrigues Resende
}

\section{RESUMO}

Neste artigo há a proeminente preocupação historiográfica em relação ao cotidiano escolar, privilegiando a análise ainda hesitante na historiografia da educação brasileira: a cultura material escolar da escola primária. O objetivo deste estudo foi analisar o livro Estudo dirigido de educação moral e cívica, datado de 1975, em busca de discutir algumas questões aqui propostas: Por que esse livro foi trabalhado em sala de aula? Qual objetivo de aplicação? Em que contexto ele está inserido? Quais os valores que estão sendo transmitidos por meio desse livro? Quais práticas são possíveis de serem reveladas por detrás desse material? Com a metodologia proposta por Abreu (2012), foi possível perceber que o livro foi trabalhado em sala de aula por uma obrigatoriedade legal e seu intuito era moldar os sujeitos com valores morais, religiosos, patriotas, higiênicos e legais.

Palavras-chave: História. Cultura Material Escolar. Valores. Educação Moral.

\section{ABSTRACT}

In this article there is a prominent concern in relation to the historiographical school routine, privileging the analytical deepening yet hesitant in the historiography of Brazilian education: school material culture of primary school. The objective of this study was to analyze the book Guided Study of Moral and Civic Education, dating 1975 , seeking to discuss some issues proposed here: why was this book worked in the classroom? What was the applicatio purpose? In which context is it inserted? What are the values being transmitted through this book? What practices are likely to be revealed behind this material? With the methodology proposed by Abreu Jr (2012), it could be notices that the book was worked in the classroom by a legal obligation and its purpose was to frame the subject with moral, religious, patriotic, hygienic and legal values.

Keywords: History. Culture school supplies. Values. 


\section{INTRODUÇÃO}

A paixão pelo detalhe microscópico é alvo de inspiração dos microhistoriadores. Carlo Ginzburg (2007, p. 250) retrata que "[...] o primeiro a arvorar a noção de 'micro-história' como uma autodefinição foi o estudioso americano George R. Stewart, em 1959 [...]” A insatisfação com o modelo macroscópico fez com que historiadores italianos como Giovanni Levi, Simona Cerutti, Edoardo Grendi e Carlo Ginzburg, além de autores de outros países, se ocupassem da história local, dos microacontecimentos e das microanálises de pequenos objetos. De maneira semelhante, Peter Burke (2005) discute a antropologia histórica, buscando recuperar conceitos apropriados para designar o trabalho da história cultural sob o olhar microscópico.

Segundo Razzini (2008), o século XIX foi marcado pela universalização da educação e expansão escolar, ancorada nos princípios de obrigatoriedade, gratuidade e laicidade. Com isso, há a ampliação do mercado material escolar, havendo o abandono da pena de ganso pela pena metálica, uso de papel barato, giz e lousa. Em meados de 1930, haviam tabuleiros de areia, ardósias para serem escritas com pedras, estojos de madeira, borrachas e goma arábica. Todos esses objetos merecem a atenção do micro-historiador e é angustiador pensar que muitos desses objetos foram perdidos na passagem ininterrupta e eterna dos anos.

Para conhecer um pouco mais sobre os manuais escolares, Alain Choppin (2000) oferece grandes contribuições. Esses manuais transmitem um sistema de valores, ideologia e cultura, participando de um processo de socialização, aculturação e doutrinamento. Possuem também, um conjunto de informações destinadas a um público que se pretende atingir, além de estarem ligados ao contexto temporal e social no qual se vinculam. Por isso, é preciso refletir sobre os manuais como materiais de investigação, indagando quem são os autores, quais os valores transmitidos e qual o papel destes livros na sociedade. Nesse aspecto será focalizada esta análise: no trabalho com a cultura material escolar, indagando o que o material representa sobre as práticas escolares.

Abreu Júnior (2012) salienta que a cultura material escolar pode ser ocupada por três vertentes: dos materiais escolares, dos agentes educacionais e do contexto sócio-político. Neste caso, a atenção especial será dada ao material escolar e ao contexto em que estava inserido na época que funcionou como instrumento didático.

A análise que gerou este trabalho foi feita a partir do livro Estudo dirigido de 
educação moral e cívica, datando 1975. O livro foi encontrado com escritos a lápis e com as páginas recortadas. Então, surgiu a reflexão que as obras, utilizadas como instrumentos didáticos, também podem ser consideradas de forma semelhante aos cadernos escolares: como fonte histórica. Viñao (1988, p. 15) defende que os cadernos escolares são ao mesmo tempo “[...] uma produção infantil, um espaço gráfico e um produto da cultura escolar. Os cadernos podem ser uma fonte rica de informações, que permitem ao pesquisador adentrar na "caixa preta" ${ }^{1}$ do sistema de ensino.

Quer seja da história do currículo, das instituições educativas, das culturas e memórias escolares, ou de dentro delas, das disciplinas, das atividades e dos exercícios escolares, os historiadores da educação encontraram nos cadernos escolares vantagens indubitáveis [...] (VIÑAO, 1988, p. 16).

De forma semelhante, Hébrard (2001) expõe que o caderno é um instrumento comum desde o século XVI, compostos por uma parte essencial do tempo escolar. Neles podem-se encontrar exercícios de todos os tipos: cópias, listas, tabelas e agendas.

Após essa apresentação sobre o exercício peculiar no qual o historiador deve se submeter, é relevante abordar pesquisas que vem sendo desenvolvidas nessa área. Laerthe Moraes de Abreu Júnior (2009) analisa práticas escolares selecionadas do livro de memórias do escritor brasileiro Humberto de Campos, desvendando práticas repressoras, mas carregadas de afetos e simbolismo por parte do autor. Outro texto de Abreu Júnior e Costa (2007) demonstra como a formação de agentes de educação rural na escola D. Luiz de Castro, em Braga Portugal, trazia uma proposta pedagógica inovadora, integrando conhecimento com prática cultural, em pleno período da ditadura militar. O livro organizado por Castro (2011) a análise feita por Mancini (2010), a valorização da arquitetura escolar presente em Funari e Zarankin (2005), o estudo dos manuais escolares feito por Azevedo (2011), o trabalho com jornal de Cunha (2013), a pesquisa com mobiliários de Castro e Silva (2011), dentre outros trabalhos, conduziram-se no sentido de buscar memórias e práticas educativas com os materiais escolares. Análises como essas citadas anteriormente precisam ser reconhecidas e dignas de destaque por oferecerem contribuições jamais pensadas na

\footnotetext{
${ }^{1} \mathrm{O}$ conceito de "caixa preta" foi utilizado no sentido de ilustrar que a cultura material escolar pode ajudar o pesquisador a desvendar as práticas que permanecem dentro das instituições escolares. A definição de "caixa preta", então, foi utilizada no mesmo sentido dado por Sirota (1994), quando defende que a sala de aula permaneceu durante muito tempo como uma "caixa preta", parecendo não haver, em seu interior, aspectos que, não sendo familiares ou rotineiros, merecessem investigação. Aqui, o intuito é entrar na caixa preta por meio da cultura material escolar.
} 
investigação das marcas singulares dos sujeitos da história local.

Por meio da análise de um livro é possível imaginar a materialidade de uma prática. O objetivo deste texto é compreender, analisar e indagar o que o livro Estudo dirigido de educação moral e cívica, diz sobre as práticas escolares. Por que esse livro foi trabalhado em sala de aula? Qual objetivo de aplicação do mesmo? Em que contexto ele está inserido? Quais os valores que estão sendo transmitidos por meio deste livro? Quais práticas são possíveis de serem reveladas por detrás desse material? Vale salientar que a análise foi feita do livro como um todo, mas necessita de maiores aprofundamentos, pois devido ao objetivo deste texto, que é ser mais sucinto, não teria condições de discutir todos os aspectos contidos no material. Serão discutidos, então, os aspectos metodológicos para se alcançar o propósito descrito.

\section{ASPECTOS METODOLÓGICOS}

Segundo Abreu Júnior (2012, p. 170) a pesquisa voltada para cultura material escolar não se fundamenta somente na concretude dos objetos em si, mas também “[...] nas atividades e nas relações que essa produção promove na e com a cultura". Alguns marcos são apontados, por esse autor, como caminhos possíveis de análise.

O paradigma indiciário é o primeiro marco, obtido da obra Mitos, emblemas e sinais de 1991, de Carlo Ginzburg. Esse consiste no olhar cuidadoso para o micro, para os detalhes e particularidades. A partir do conto A carta roubada de Edgar Alan Poe (2008) foi proposto o segundo marco, que diz respeito à atenção aos mais corriqueiros objetos, assumindo uma posição de detetive nessa busca. O estranhamento é o terceiro marco, que consiste em olhar os objetos como inabituais. $\mathrm{O}$ efeito Madeleine, extraído do livro No caminho de Swann (1956) é o quarto marco e significa olhar para os detalhes e pormenores dos objetos.

A partir dos marcos anteriormente descritos, o intuito foi observar o micro e com atitude de detetive, vasculhar materiais provenientes da minha família. Visitei tios e avôs na busca de um material escolar que por mais corriqueiro que fosse trouxesse por trás de si, uma história permeada por valores, práticas, ideologias e saberes. Encontrei o livro Estudo dirigido de Educação Moral e cívica, de Avelino Antônio Correa (1975), em uma estante empoeirada, misturado a outros livros. O livro foi encontrado sem capa e com várias páginas recortadas. Por que dessas páginas recortadas? Será que as figuras serviram para outro trabalho escolar? Não tive pistas de onde o livro veio e nem por quem foi utilizado, mas os exercícios estavam feitos 
todos a lápis. Na primeira página estava mencionado que o público a que se dirige é de " 5 a à $6^{\text {a }}$ série do primeiro grau".

O livro despertou a vontade de pesquisar os materiais escolares, olhando para objetos corriqueiros, numa atitude de estranhamento, dirigindo o olhar para os detalhes. Essa é a proposta aqui apresentada: um artigo objetivando a análise de um documento escolar. Objetos sofrem a deterioração com o tempo que não cessa. Materiais são descartados e mal cuidados sem interesse em preservar a história. Essas ações permearam, muitas vezes, no hábito dos sujeitos. Como não pensar que um material guarda memórias pelas veredas do passado? Como não refletir que um simples objeto pode significar grandes eventos de trajetórias individuais e coletivas? Com isso, o livro foi analisado com cuidado, a partir dos aspectos metodológicos propostos por Abreu Júnior (2012) e primeiramente será discutido o contexto de inserção da obra.

\section{CONTEXTO DE INSERÇÃO DO LIVRO}

Em 1975, ano de publicação do livro, vivia-se no Brasil a Ditadura Militar, com censuras, perseguições políticas, supressão de direitos constitucionais e repressão aos que eram contra o regime militar. A sociedade brasileira, na primeira metade do século XX, sofreu várias transformações como o esforço pela escolarização, o surgimento do rádio e do cinema. Conforme Abreu Júnior (2012, p. 175) uma característica marcante dessa época era a "falta". "Principalmente, falta de cuidados com a saúde, com a moral, com a educação e com a própria raça", fazendo-se necessária uma educação em busca de uma sociedade civilizada.

A Lei 869 de 12 de setembro de 1969 estabeleceu, em caráter obrigatório, como disciplina e, também, como prática educativa, a Educação Moral e Cívica em todos os sistemas de ensino no Brasil. A disciplina objetivava o fortalecimento da unidade nacional, o sentimento de solidariedade humana, o aprimoramento do caráter, o preparo do cidadão para o exercício das atividades cívicas com fundamento na moral, no patriotismo e na ação construtiva, visando o bem comum. Essa disciplina permaneceu nos currículos até 1993, quando foi revogada pela Lei 8663. É nesse contexto sócio, político e ideológico que o livro foi publicado, com vistas a educar, civilizar, corrigir e doutrinar os alunos. Buscar-se-á perceber o que esse material diz sobre as práticas escolares. 


\section{ANÁLISE DOS CONTEÚDOS DO LIVRO}

Alguns temas permearam o livro analisado como um todo e essas categorias serão abordadas a seguir.

\subsection{Princípios morais}

Antes de iniciar o capítulo 1, o autor do livro expõe o quanto a obra é importante para "indicar os caminhos da felicidade". Deixa, assim, seis observações para o aluno antes de manusear o material:

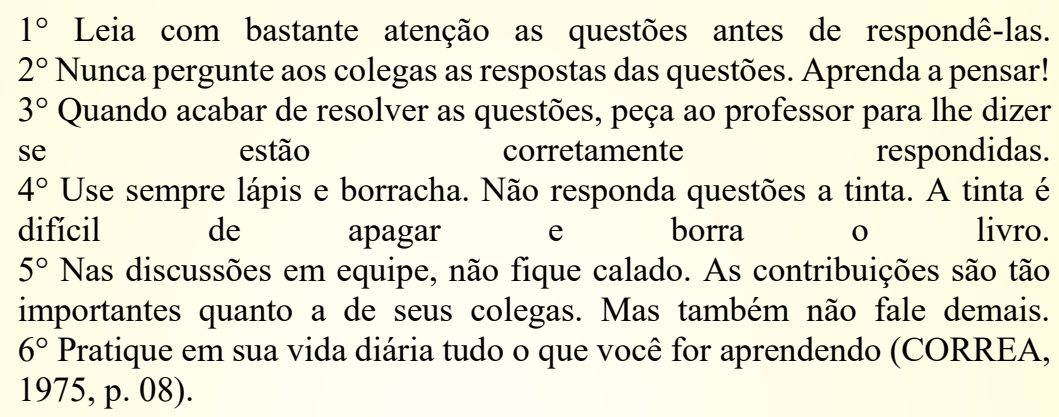

Nessas observações, percebe-se o quanto é necessário que o livro seja bem cuidado e utilizado pelo aluno. Além disso, o quanto é importante manter o equilíbrio na sala de aula: não ficar calado nem falar demais. A moral já permeia as primeiras instruções: "não pergunte ao colega as respostas das questões, aprenda a pensar."

Nos primeiros capítulos é discutida a necessidade de ser feliz e aprender a lutar, combater, ser forte, bravo e herói. São abordadas, também, as virtudes associadas à moral, como não ser egoísta, não ter vícios, não falar mal dos outros, amar e respeitar os pais e professores e ter bons hábitos. Além disso, há os deveres dos alunos que consistem em não faltar às aulas sem motivo, não colar nas provas e cuidar dos materiais escolares.

Os princípios morais são os temas mais fortes presentes no livro. Enfatiza-se sobre a necessidade de ouvir a voz da consciência, como observado no texto a seguir:

Encontrou 50 mil e devolveu

Um homem, David Canetti, desembarcou ontem cedo em Congonhas, como centenas de outras pessoas. Na mão, uma maleta com cerca de 9 mil dólares (mais de 50 mil cruzeiros). Deixou o aeroporto, apanhou um táxi e foi para o Hotel Jaguará. Poucos minutos depois, deu pela falta da maleta e dos 9 mil dólares: havia esquecido tudo no banco traseiro do táxi de Nelson Domingos Peres. Para David Canetti, isso era o que menos poderia esperar em sua viagem a São Paulo: na maleta, além do dinheiro, muitos 
documentos, seu passaporte e outras coisas importantes. Lamentando-se ele foi almoçar com um amigo. E ainda se lastimava quando viu o motorista de táxi entrar pela porta do restaurante com a maleta. Nelson então contou o que houve: da rua Major Quedinho, onde fica o Jaguará, foi para São Bernardo do Campo e, lá, descobriu a maleta no banco de trás do carro. Não a abriu. Levou-a para o coordenador de seu ponto e, juntos resolveram ver se descobriam de quem era: do passageiro para São Bernardo ou daquele que ficara no Hotel Jaguará. A fotografia do passaporte confirmou o dono e ele foi devolvê-la no hotel. Em troca, uma gratificação de 50 cruzeiros e a consciência tranquila. (CORREA, 1975, p. 28).

Esse texto, extraído do jornal $O$ Estado de São Paulo, em 28 de Agosto de 1972, foi objeto de estudo dos estudantes das $5^{\mathrm{a}} \mathrm{s}$ e $6^{\mathrm{a}} \mathrm{s}$ séries. Ele demonstra como as virtudes precisavam ser incorporadas pelos alunos. Mas como as atividades eram feitas? Em grupos ou individualmente? As práticas cotidianas também eram embasadas na moral? Alguns exercícios propõem que sejam feitas discussões em equipe, outros solicitam que sejam feitas atividades individuais. Exemplar desses é o teste da personalidade que busca analisar o caráter de cada aluno, salientando: "Você não é obrigado a mostrar o resultado a ninguém. Mas seja sincero consigo mesmo" (CORREA, 1975, p. 16).

Em outra atividade, propõe-se que o aluno responda algumas perguntas sobre a moral. Observa-se que as respostas às essas perguntas foram rasuradas várias vezes, como é possível visualizar na imagem:

Figura 1: Discussão sobre moral em equipe Atividade proposta em equipe a partir de valores morais.

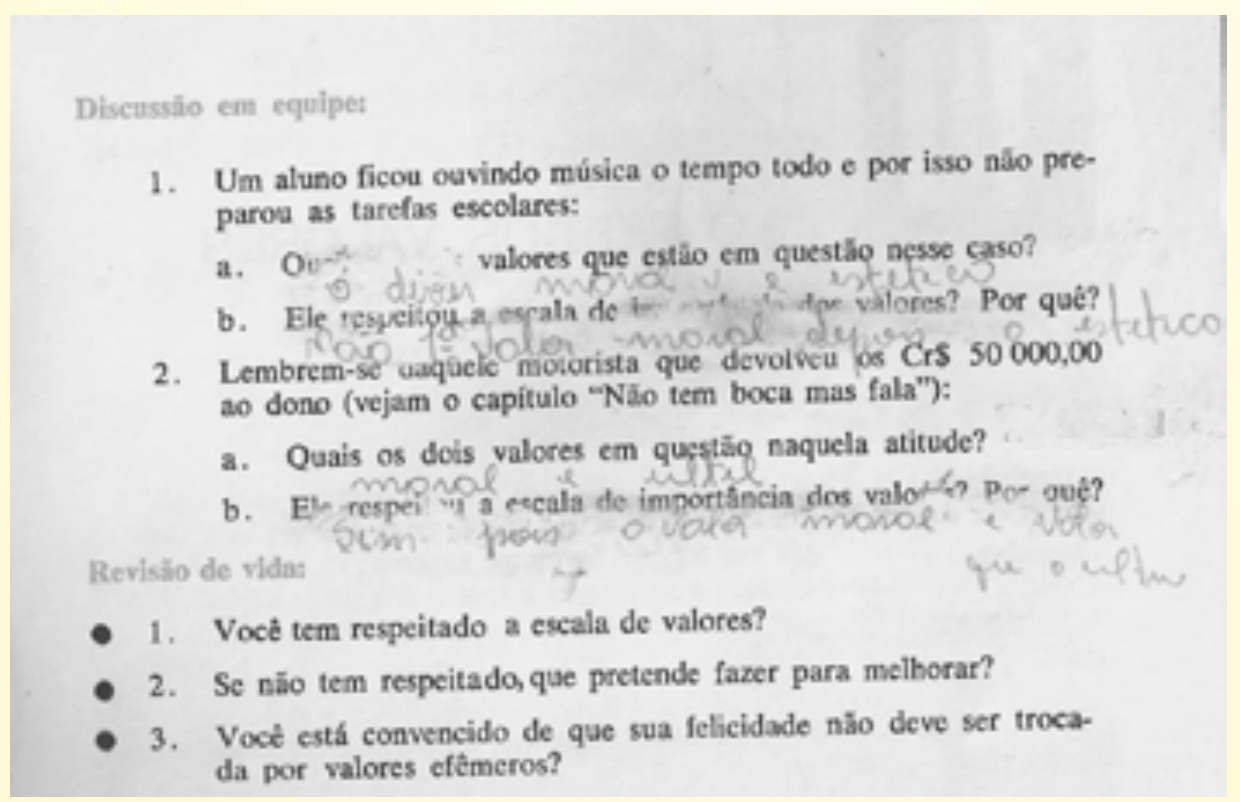

Fonte: (CORREA, 1975, p. 45). 
Manchas de borracha escondem o sentimento escrito pelo aluno. A força para apagar as palavras desmancha até mesmo a pergunta proposta pelo livro. Por que essas respostas foram tão rasuradas? O que o aluno tinha escrito antes? Por que apagou? Por que as próximas perguntas não foram respondidas? São indagações que jamais serão descobertas com a análise do material, uma vez que essas demandariam uma metodologia mais acurada.

Choppin (2000, p.109) defende que "los manuales transmiten un sistema de valores, una ideologia, uma cultura", podendo possuir um conjunto de técnicas de manipulação e constituindo-se de um instrumento de poder. O livro analisado busca construir um povo ordeiro, civilizado e saudável moralmente.

\subsection{Discurso higienista}

Abreu Júnior e Carvalho (2012) discutem questões sobre o discurso médicohigienista no Brasil do início do século XX. Os médicos defendiam uma pedagogia salvacionista para os males que afligiam o povo brasileiro. Havia um discurso propondo cuidados com a higiene corporal, a saúde, ligando a educação moral com a educação do corpo. Os males e vícios eram inimigos do progresso.

Essa preocupação também aparece no livro de educação moral e cívica, propondo que para estudar com mais facilidade são importantes: “[...] ambiente limpo, bem iluminado e o mais silencioso possível" (CORREA, 1975, p. 25), sentar-se na cadeira corretamente para evitar a moleza e a deformação do corpo, fixar um horário de estudos de forma que tenha dez minutos de intervalo, além de que esse horário deve ser fixo todos os dias, mesmo sem vontade para tal. Na obra também ficaram explícito os valores legais.

\subsection{Os valores legais}

Os valores legais estavam presentes. No capítulo 6 do livro, discute-se como saber aproveitar a liberdade que "Deus nos deu". Além de instruir sobre o que é a justiça, as leis e a constituição. "É preciso fazer o bem e evitar o mal!" (CORREA, 1975, p. 34). Discute também o regulamento da escola e as normas a serem cumpridas. Fica explícito o conceito de democracia, discutindo que a democracia no Brasil é indireta e representativa. Fala-se no poder legislativo, executivo e judiciário.

Pela instrução dada no material, é possível pensar em práticas efetuadas de 
forma rígida, baseada em princípios e regras. A liberdade do aluno deveria se pautar dentro dos moldes civilizatórios propostos. O material, em todos os capítulos, se mostra interativo e dinâmico, oferecendo jogos de palavra cruzada, caça palavras, imagens e histórias em quadrinhos, como pode ser observado na imagem a seguir, retirada do livro, na página 31 :

Figura 2: O caminho a seguir

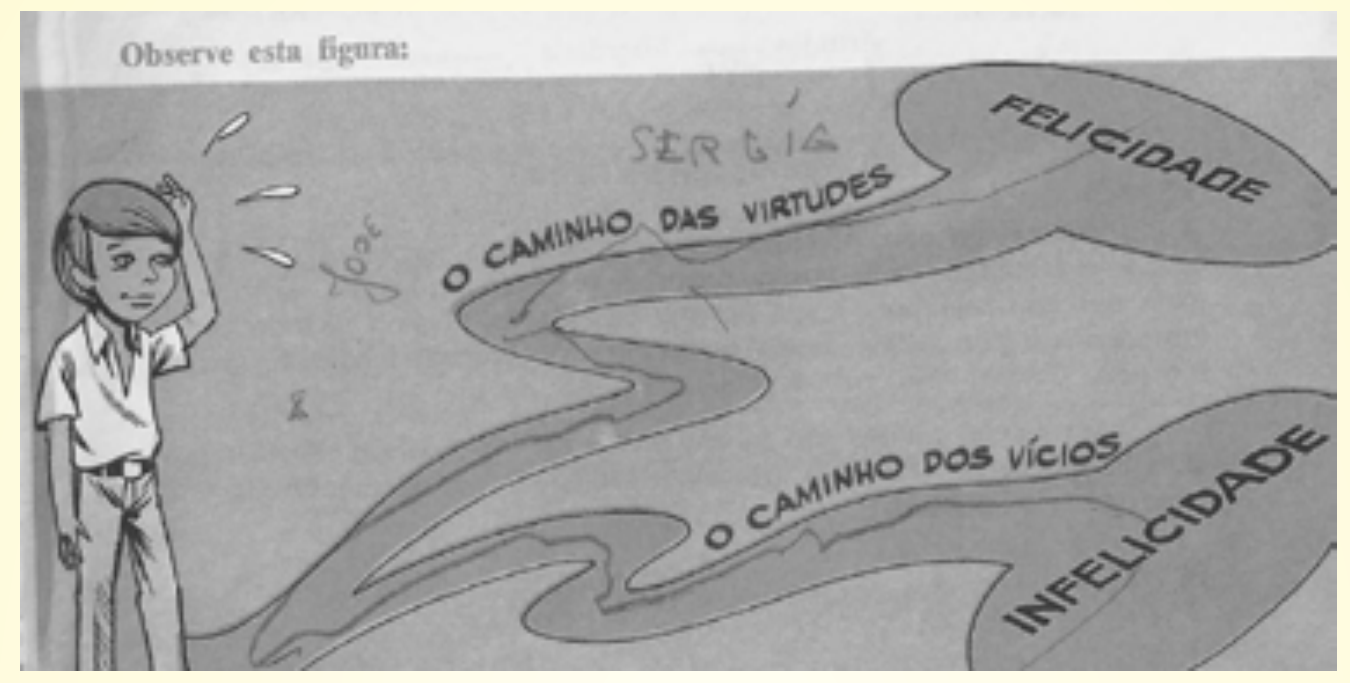

Fonte: (CORREA, 1975, p. 31).

Nessa imagem o aluno desenha, com lápis, os dois caminhos: das virtudes e dos vícios. Por que isso acontece? O que esses traçados nos mostram? Como podem ser interpretados? Na tentativa de imbricar nos alunos os valores necessários, a religiosidade também se fez presente.

\subsection{Religiosidade}

Colocar Deus como o centro do universo, igualmente, é um aspecto destacado no livro. Conta-se sobre a história de Adão e Eva, mencionando que "[...] a morte foi um dos castigos da desobediência dos primeiros homens" (CORREA, 1975, p. 52). Com isso, quem não praticar as leis de Deus, não será feliz. Após cada discussão feita, são apresentadas perguntas em que o aluno terá que responder corretamente. Exemplar dessas é "Por que Deus nos fez inteligentes e livres?"

Pode-se imaginar que as aulas eram permeadas por rituais religiosos, como orações e pedidos. As crianças eram estimuladas a viver sob sacrifícios para não pecar. A Constituição Imperial de 1824, estabelecia que o catolicismo era a religião oficial do Brasil. No Manifesto dos pioneiros da educação nova, de 1932, documento que se 
tornou o divisor de águas da educação brasileira, se defendia a escola pública, laica, gratuita, centrada na coeducação. Posteriormente, a lei 9.394 de 20 de dezembro de 1996, com redação dada pela Lei n 9475 , de 22 de julho de 1997, sanciona que:

Art. $33^{\circ}$ - O ensino religioso, de matrícula facultativa, é parte integrante da formação básica do cidadão e constitui disciplina dos horários normais das escolas públicas de ensino fundamental, assegurado o respeito à diversidade cultural religiosa do Brasil, vedadas quaisquer formas de proselitismo (BRASIL, 1997).

Com isso, o Estado é considerado, a partir dessa, como sendo laico e as instituições escolares, da mesma forma, passam a não desenvolver práticas pautadas em determinado tipo de religião.

\subsection{Patriotismo}

“Ama com fé e orgulho a terra em que nasceste!" (BILAC apud CORREA, 1975, p. 70). É dessa forma que se introduz o capítulo sobre patriotismo, defendendo o amor ao lar, à família e à pátria.

Apresentam a figura de Joaquim José da Silva Xavier como o patrono cívico do Brasil. Logo, há uma história em quadrinhos sobre a independência do Brasil, propondo aos alunos a memorização de quem foram algumas figuras ilustres da história, como: D. Pedro I, José Bonifácio de Andrada e Silva, Henrique Dias, André Vidal de Negreiros, Duque de Caxias, Oswaldo Cruz, dentre outros.

Pensando nos movimentos de pesquisas em história, o termo "Nova história" foi empregado com vistas a valorizar sujeitos históricos não estudados em detrimento de figuras consideradas como heroínas. É um tipo de história que busca evitar qualquer tipo de determinismo e positivismo, estabelecendo relações dialéticas. Matos (2010) expõe que

esse movimento acabou por se dividir em três fases distintas: a primeira, iniciada em 1920 e liderada por Lucien Febvre e Marc Bloch, se estenderia até 1945, caracterizada pelos embates contra a História tradicional "metódica" ou erroneamente chamada "positivista"; a segunda, de 1946 até 1968 e "dominada" pela presença de Fernand Braudel, centrou-se mais sobre os conceitos de estrutura e conjuntura, e acabou por aproximar-se muito, segundo Burke, de uma escola, com novos métodos e propostas para a constituição de uma História serial e de longa duração; a terceira e não última se iniciaria em 1968, liderada por Jacques Le Goff e Georges Duby, e seria marcada pela fragmentação: "nos últimos vinte anos, [...] alguns de seus membros transferiram-se da história socioeconômica para a sociocultural, enquanto outros estão redescobrindo a história política e 
mesmo a narrativa" (BURKE, 1997, p. 13). Além dessas três fases distintas, atualmente fala-se em uma quarta geração herdeira dos Annales, que seria a Nova História Cultural. Liderada pelos historiadores Roger Chartier e Jacques Revel, teria sofrido influência da crítica de Michel Foucault.

A visão da história passada para os alunos, público alvo do livro analisado, era uma visão determinista. Todavia, com o risco de cometer um anacronismo, precisa-se pensar em uma época de represálias, poder, torturas: era a Ditadura Militar instalada na sociedade. Era a lei que sancionava um conteúdo de Educação Moral e Cívica obrigatório, com objetivo de civilizar a nação.

No livro também há um capítulo mencionando os objetivos nacionais, que são: a integridade territorial, integração nacional, a soberania nacional, a democracia representativa e a paz social. No que diz respeito à defesa da Pátria, mostra-se a importância do serviço militar como forma de segurança nacional. Os símbolos nacionais são estudados de forma contundente, explicando como se usa a bandeira, quando, em que horários, quais as posições próprias, atitudes, significados e proibições.

\section{CONSIDERAÇÕES FINAIS}

A Lei 869 de 12 de setembro de 1969 estabeleceu, em caráter obrigatório, como disciplina a Educação Moral e Cívica e essa permaneceu nos currículos até 1993. Esse trabalho buscou analisar e compreender o que o livro Estudo dirigido de educação moral e cívica, datando 1975, representa sobre as práticas.

Esse livro foi trabalhado em sala de aula por uma obrigatoriedade legal e seu objetivo era moldar os sujeitos com valores morais, religiosos, patriotas, higiênicos e legais. O contexto em que o livro está inserido é de Ditadura Militar em que o Governo tenta disseminar junto à população a ideia de que a sociedade brasileira convivia em harmonia.

O livro apresenta imagens, história em quadrinhos, caça palavras e cruzadinhas. Foi encontrado sem capa e com várias páginas recortadas. As atividades foram feitas à lápis e algumas deixaram rastros de um intenso trabalho de desmanchar a resposta já escrita. A análise de um material, como esse pesquisado, demanda maiores aprofundamentos para desvendar os porquês indagados no texto.

Contudo, é possível pensar nas práticas escolares mediadas por regras, normas e disciplina. O professor era visto como elemento central capaz de inculcar o planejamento cívico e técnico de educação nos alunos. Com isso, as práticas deveriam 
articular grêmios estudantis, desfiles e comemorações, fazendo a escola afigurar-se de uma sociedade democrática em miniatura. E para terminar, na última página do livro, argumenta-se que "a vida é combate. Não se deixe vencer pelo desânimo. Nem pelas derrotas ocasionais. O Brasil precisa de você!" (CORREA, 1975, p. 156).

\section{REFERÊNCIAS}

ABREU JÚNIOR, Laerthe Moraes. Por uma metodologia em cultura material educativa: trabalho com documentos sobre educação na primeira metade do século XX. Viçosa: Ver. Educação em Perspectiva, v. 3, n. 1, p. 167-184, 2012.

Disponível em:

http://www.seer.ufv.br/seer/educacaoemperspectiva/index.php/ppgeufv/article/viewF ile/253/81. Acesso em: 06 de Out. de 2015.

ABREU JÚNIOR, Laerthe Moraes. O dedo mindinho de Humberto Campos: Micromemórias de práticas escolares da educação brasileira do final do século XIX.

Revista Trajetos, Fortaleza, v.7, n.13, $1^{\circ}$ sem. 2009.

ABREU JÚNIOR, Laerthe Moraes; CARVALHO, Eliane Vianey de. O discurso médico-higienista no Brasil do início do século XX. Trabalho Educação e Saúde, v.10, n.3, p. 427-451, 2012. Disponível em:

$<$ http://www.scielo.br/scielo.php?pid=S1981-

77462012000300005\&script=sci_arttext.> Acesso em 06 out. 2014.

ABREU JÚNIOR, Laerthe Moraes; COSTA, Maria Judite Rodrigues. A formação de agentes de educação rural na Escola D. Luiz de Castro, em Braga, Portugal (19571977). In: PEREIRA, Lúcia Helena Pena; OLIVEIRA, Wanderley Cardoso de (Org.). Práticas educativas: Discursos e produção de saberes. Rio de Janeiro: Epapers, 2007, p. 233-258.

AZEVEDO, Crislane Barbosa. Manuais didáticos no início do século XX em Sergipe: cultura material escolar dos grupos escolares. História [online], v.30, n.2, p. 100-125, 2011. Disponível em:

$<$ http://www.scielo.br/pdf/his/v30n2/a06v30n2.pdf.> Acesso em: 26 dez. de 2015.

BRASIL. Decreto-Lei no 869, de 12 de Setembro de 1969. Dispõe sobre a inclusão da Educação Moral e Cívica como disciplina obrigatória, nas escolas de todos os graus e modalidades, dos sistemas de ensino no País, e dá outras providências.

Diário Oficial [da República Federativa do Brasil], Brasília, DF, v. 5, 15 set. p. 7769, 1969.

BRASIL. Lei n ${ }^{\circ}$ 9.475, de 22 de julho de 1997. Dá nova redação ao art. 33 da Lei nº 9.394, de 20 de dezembro de 1996, que estabelece as diretrizes e bases da educação nacional. Diário Oficial [da República Federativa do Brasil], Brasília, 1997. 
BURKE, Peter. O que é história cultural. Rio de Janeiro: Zahar, 2005.

CASTRO, César A. (Org.). Cultura material escolar: a escola e seus artefatos (MA, SP, PR, SC e RS, 1870-1925). São Luis: EDUFMA, Café \& Lápis, 2011.

CASTRO, Raquel Xavier de Souza; SILVA, Vera Lucia Gaspar da. Cultura material da escola: entram em cena as carteiras. Educar em Revista [online], n.39, p. 207-224, 2011. Disponível em: http://www.scielo.br/pdf/er/n39/n39a14.pdf. Acesso em: 26 dez. de 2015.

CHOPPIN, Alain. Passado y presente de los manuales escolares. Madrid: Biblioteca Nueva, 2000.

CORREA, Avelino Antônio. Estudo dirigido de educação moral e cívica: da $5^{\mathrm{a}}$ à $6^{\text {a }}$ série, $1^{\circ}$ grau. São Paulo: Ática, 1975.

CUNHA, Maria Teresa Santos. Das mãos para as mentes: protocolos de civilidade em um jornal escolar/SC (1945-1952). Educação rev. [online]. 2013. n.49, p. 139159. Disponível em: http://www.scielo.br/pdf/er/n49/a09n49.pdf. Acesso em: 26 Dez. de 2015.

FUNARI, Pedro Paulo; ZARANKIN, Andrés. Cultura Material escolar: o papel da arquitetura. Pró-posições, Campinas, n. 16, v. 1, p. 135-144, 2005.

GINZBURG, Carlo. Micro-história: duas ou três coisas que sei a respeito. In: GINZBURG, Carlo. O fio e os rastros. São Paulo: Companhia das Letras, 2007. p.249-279.

HÉBRARD, Jean. Por uma bibliografia material das escritas ordinárias: o espaço gráfico do caderno escolar (França- séculos XIX e XX). Revista Brasileira de História da Educação. Campinas, SP, n¹, p. 1115-141, jan.-jun. 2001.

MANCINI, Ana Paula Gomes. História e cultura material escolar: o caso de dourados, MS, Brasil (1940-1970). Educação e Fronteiras, Dourados, v. 3, n 5, p. 45-62, 2010. Disponível em:

$<$ http://www.periodicos.ufgd.edu.br/index.php/educacao/article/viewFile/1989/1073 >. Acesso em: 26 dez. de 2015.

MATOS, Júlia Silveira. Tendências e debates: da escola dos annales à história nova. Rio Grande: Historiæ, p. 113-130, 2010. Disponível em:

www.seer.furg.br/hist/article/download/2283/1183. Acesso em 06 de Out. de 2015.

RAZZINI, Márcia de Paula Gregório. Instrumentos de escrita na escola elementar: tecnologias e práticas. In: MIGNOT, Ana Chrystina Venancio (Org.). Cadernos à vista: escola, memória e cultura escrita. Rio de Janeiro: EdUERJ, 2008, p. 15-33.

SIROTA, Régine. A escola primária no cotidiano. Porto Alegre: Artes Médicas, 1994.

VIÑAO, Antonio. Tiempos escolares, tempos sociales. Barcelona: Ariel, 1998. 
Recebido em: Set/2016

Aprovado em: Dez/2016 